\title{
Battery Electric Vehicle Global Adoption Practices and Distribution Grid Impacts
}

\author{
A Preliminary Case Study for Delhi, India
}

Girish Ghatikar $^{1} \cdot$ Akshay Ahuja $^{2}$ (D) Reji Kumar Pillai ${ }^{2}$

Received: 2 May 2017 / Accepted: 17 September 2017 / Published online: 11 October 2017

(c) Springer Nature Singapore Pte Ltd. 2017

\begin{abstract}
Electric vehicles (EV) represent a large market opportunity to address macro- and micro-level carbon emissions, electric grid integration, and technological advances. Studies forecast that by $2040,25 \%$ of the global car fleet will be EVs, leading to large carbon reduction in cities. India's National Electric Mobility Mission Plan plans to deploy six-to-seven million hybrid and battery electric EVs by 2020. This significant challenge to accelerate deployment of EVs in India's nascent market requires an understanding of global EV deployment practices and their impacts on the electric grid-primarily the distribution system with last-mile connectivity to the consumers. This study provides a contextual overview of battery-based EV (BEV) global deployment practices and unravels their impacts on the Delhi's distribution grid. The study reviewed global practices for incentives, technologies, charging infrastructure, and demonstrations to contextually recommend BEV adoption strategies in India. The study conducted a limited and preliminary case study for impacts on Delhi's power systems. Recommendations are provided to accelerate BEV adoption, consumer engagement, and integrated electric grid for the nascent transportation eco-system in India.
\end{abstract}

Girish Ghatikar

Ghatikar@gmail.com

Akshay Ahuja

Akshay@indiasmartgrid.org

Reji Kumar Pillai

Reji@rejikumar.com

1 Electric Power Research Institute, Palo Alto, CA, USA

2 India Smart Grid Forum, New Delhi, India
Keywords Battery electric vehicles - Best practices . Vehicle grid integration - Distribution grid impacts $\cdot$ Power systems

\section{Introduction and Background}

Electric vehicles (EV) represent a large market opportunity to address macro- and micro-level carbon emissions, electric grid integration, and technological advances. The term, $\mathrm{EV}$, references to hybrid, plug-in, battery electric, and fuel cell vehicles. Studies forecast that by $2040,25 \%$ of the global car fleet will be EVs, leading to city-level reduction in air pollution [1]. In India, $80 \%$ of crude oil imports drive $30 \%$ of primary energy, and majority of this is used by the transportation sector [2]. India's oil import bill is USD 120 billion with an anticipated increase to USD 230 billion by 2023 [3]. This transportation sector is expected to expand fueled by the economic development, oil-price declines, government policies to develop highway and road infrastructure, and make in India programs that promote local manufacturing [4]. In 2015-16, India's market for internal combustion engine (ICE) vehicles was 20.5 million [5]. This ICE vehicle market comprised of passenger, commercial, two-, and three-wheelers. The two-wheelers and passenger vehicles formed majority of sales with $80 \%$ and $14 \%$ market share, respectively. The carbon emissions by the ICE transportation sector and oil imports pose challenges for India's sustainable and affordable growth, similar to the challenges posed by carbon emissions from electricity generation and consumption sectors.

This study focus is on battery-based EVs (BEVs) that connect to a power source to charge a battery. Large-scale and accelerated deployments of BEVs in India require an 
understanding of global deployment practices, the policypush to encourage early adoption (e.g., incentives), and an understanding of BEV impacts on the electric gridprimarily the distribution system with last-mile connectivity to the consumers. This integrated planning of macro national- and state-level programs, and micro regionaland city-level electricity distribution systems' readiness and market structures are essential for large-scale and accelerated deployments of BEVs in India. Albeit not the focus of this study, the integrated planning can also enable the use of BEVs for grid services and integrate renewable generation.

The goal of the study is to accelerate and scale the adoption of BEVs in India and assist the Indian national and state regulators meet their electric mobility goals. The goal is achieved through an integrated contextual overview of global BEV deployment practices and analyzes of BEV impacts on the distribution grid. The main objectives of the study are:

1. Review global adoption practices for large-scale deployments of BEVs.

2. Analyze the Indian scenarios for EV initiatives and unique deployment needs.

3. Conduct preliminary distribution system analysis and case study for a distribution utility in Delhi.

4. Assess distribution system impacts from the adoption of BEVs in Delhi.

5. Propose recommendations to accelerate and scale BEV adoption.

\section{Background}

To decarbonize the transportation sector, in 2012, the Government of India's (GOI) Ministry of Heavy Industries (MoHI) launched National Electric Mobility Mission Plan (NEMM) to deploy 6 to 7 million hybrid and EVs (includes 2- and 4-wheelers) by 2020. In support, the GOI has allotted INR 1,000 crores or USD 150 million for faster adoption and manufacturing of (hybrid and) electric vehicles scheme (FAME) for the financial years, April 2015-16 and 2016-17 [6]. The budget for the FAME scheme is allocated for the following components: demand incentives, technology platform, pilot projects, charging infrastructure, and program operations. Of the 2016-17 budget of INR 5,350 million or USD 80.25 million, the percentage share of various components is, $51 \%, 18 \%, 7.5 \%, 3 \%$, and $0.75 \%$, respectively. The large share for demand incentive lowers the retail price of the vehicle. The demand incentive varies based on the vehicle emission levels across the following segments: twoand three-wheelers, passenger cars, light-commercial vehicles, and busses. The classifications of emissions levels across the vehicle segments are: mild-hybrid, strong-hybrid, plug-in hybrid, battery-operated electric vehicles. The lower the emissions, the higher the demand incentive based on the technical criteria prescribed in the FAME guidelines and certified by the GOI designated testing centers. In its first year, 2015-16, the FAME has made a minor dent in EV adoption with $1.3 \%$ of total hybrid and battery electric passenger vehicle sales [7]. The phase 2 of the FAME scheme for 2016-17 more than doubles the incentives to likely influence higher sales. ${ }^{1}$

India's NEMM and FAME programs and lower tax rates offered by select state-level programs are intended to encourage adoption of EVs. It should be noted that the FAME demand incentives form one component of the incentives, whereas the state- and central-level incentives further reduce the capital expenditure costs of hybrid and EVs to parity or slightly above their equivalent ICE-vehicle base case [7]. While hybrid and EV adoption rates in India have a long road ahead to meet the NEMM goals, the global adoption practices show that the readiness of the refueling infrastructure and other supporting eco-system programs are key to influence consumer's decision to own EVs. For BEVs, the deployment of charging infrastructure is determined by the extant electricity supply and the state of the grid.

The impact of BEVs on the electric grid can be minimal to significant, depending on the state of the grid, electricity supply, levels and distribution of charging infrastructure within the smart grid domains-transmission, distribution, and customer (or behind-the-meter) — and market share of BEVs. In India, there is no large-scale public demonstration to integrate EVs and grid. Vehicle grid integration (VGI) services include smart or managed charging and two-way power flow scenario, vehicle-to-grid (V2G). However, there are large-scale demonstrations for automated demand response (AutoDR) in India. One such demonstration is conducted by Delhi's distribution utility, Tata Power Delhi Distribution Limited (TPDDL), to automate DR for over 145 commercial and industrial customers. Studies have shown success and: (1) identified and characterized each consumer sector's load duration curve and aggregated power demand [8]; (2) characterized AutoDR system, including advanced metering infrastructure, data analytics, smart meters, and standards [9]; and (3) estimated the potential of DR for customers in the state of Delhi [10]. The regulatory, technologies, and utility-customer engagement findings can accelerate VGI and mitigate system upgrades.

Global adoption practices, and the BEV impacts on the grid provide an impetus to accelerate and scale India's EV adoption. The paper is organized, as follows:

- "Global Practices Driving Adoption" reviews global practices for EV adoption.

\footnotetext{
${ }^{1}$ Considered at the INR/USD foreign exchange rate of INR 66.66.
} 
- "Electric Vehicle Adopton in India: Distribution System Impacts in Delhi" summarizes state-level EV programs in India and conducts analysis of BEVs on the distribution system for the state of Delhi.

- "Conclusions and Recommended Next Steps" lists conclusions and recommendations.

\section{Global Practices Driving Adoption}

Several countries have set targets for BEV adoption. While some countries are proceeding aggressively by favorable environment for policies and incentives, others are at a nascent stage. The United States (U.S.) represents one of the largest BEV markets in the world have aggressive plans to deploy EVs with tangible incentives at both state- and federal-level, public investment and loan programs for the deployment of charging infrastructure, and aggressive R\&D investment in the key areas of grid modernization, vehiclegrid integration, and power systems interoperability. For example, In the U.S., California's Zero Emission Vehicle (ZEV) mandate requires 1.5 million BEVs by 2025 with over USD 1.1 billion public investments in the charging infrastructure with the bulk system operators and distribution utilities playing a key role in accelerating their adoption. Beginning 2015, California's building codes also require requires all new residential and non-residential buildings to install electricity infrastructure for EV charging stations [11]. The building codes and enforcement will lead to pervasive EV charging stations and enable consumers to buy electric cars. Overall in 2016, 609,629 Alternate Fuel Vehicle (AFVs) or non-ICE vehicles were registered in the European Union, up $4.1 \%$ compared to 2015. The hybrid electric vehicles $(+27.3 \%)$ followed by the electrically chargeable vehicle (ECV) segment, which saw more modest growth $(+4.8 \%)$, drove the increase. Among the big five markets, Spain $(+49.4 \%)$, Germany $(+21.9 \%)$ and the United Kingdom $(+14.9 \%)$ recorded substantial increases in non-ICE vehicle registrations. Growth in these countries was fully driven by demand for electric and hybrid electric vehicles. [12]. Similar to California, France plans for aggressive EV deployment through new building codes requiring new apartment and commercial buildings to be ready for charging infrastructure [13]. At a macro-level, to promote the EVs, Europe is planning initiatives to accelerate the deployment of EV charging infrastructure [14]. In 2016, China sold 351,000 Plug-in passenger cars, which makes it by far the largest market for plug-ins (termed, as New Energy Vehicles or NEVs in China). The increase of NEVs 2016, over 2015, was staggering $85 \%$ [15].

The following sections summarize global best practices for market share, incentives, standardization, ownership and
Table 1 Global BEV sales in 2016

\begin{tabular}{lc}
\hline Country & Sales in 2016 \\
\hline United States & 84,850 \\
Canada & 4,160 \\
Netherlands & 4,147 \\
Germany & 11,410 \\
Portugal & 756 \\
United Kingdom & 10,264 \\
Denmark & 1,373 \\
Sweden & 2,945 \\
Spain & 2,005 \\
Norway & 24,222 \\
France & 21,751 \\
Austria & 3,826 \\
India & $\sim 1,000$ \\
China & $2,66,000$ \\
\hline
\end{tabular}

operational models for VGI programs to manage grid impacts from BEV demand growth.

\section{Summary of global best practices}

The global BEV adoption rates are primarily driven by strong state- and/or country-level policies, which are targeted at the higher market share of 4 -wheelers. Table 1 provides the 20162 and 4-wheeler BEV sales for the American, European, and Asian countries $[12,16] .^{2}$ The global electric car adoption crossed the million-mark barrier to 1.26 million in 2015 [34]. India has the least per-capita BEV adoption among the countries studied.

While the availability of and access to the charging infrastructure is a determinant in nudging the consumer adoption of BEVs, initial interviews with market makers in India have revealed that the capital expenditure costs of BEVs represent a key decision influencer for consumer adoption. Albeit the BEV costs globally are falling precipitously, it still remains a key decision factor for consumers. Most policies incentivize the early adopters to for BEV purchase. Table 2 summarizes the incentives available for $\mathrm{BEVs}$ and their charging infrastructure.

The type and power levels and their charging standards determine the cost of charging station incentives. Location of charging infrastructure and BEV charging time alleviates the driver's range and charging anxiety, and enable interoperability with the charging station, third-party service providers, and the electric grid. Table 3 summarizes the key power charging standards under adoption by major countries.

\footnotetext{
${ }^{2} 2014$ is considered since we had access to the data, while understanding that the BEV adoption in 2015-16 has accelerated.
} 
Table 2 BEV and charging infrastructure incentives by key countries

\section{United States}

- EV purchased during or after 2010 is eligible for a federal income tax credit of up to USD 7,500 [18].

- Many states offer cash and non-cash incentives, such as carpool lane access and free parking. Some examples are, as follows:

Arizona: Reduced Vehicle License Tax, Carpool lane access and reduced rates for EV charging

California: Up to USD 2,500 income state tax credit rebate

Colorado: USD 5,000 tax credit

Hawaii: Carpool lane access and reduced rates for EV charging

Nevada: Carpool lane access and reduced rates for EV charging

New Jersey: Sales tax exemption

Washington DC: Excise tax exemption

\section{France [19]}

Regions have the option to provide an exemption from the registration tax (either total or $50 \%$ ) for alternative or clean fuel vehicles. Under a bonus system, starting 2016, a premium is granted for the purchase of a new electric or hybrid electric vehicle, as follows: (1) car that emits between 61 and $110 \mathrm{~g} \mathrm{CO} 2 / \mathrm{km}$, the amount of the bonus is Euro 750; (2) for a car or commercial vehicle emitting between 21 and $60 \mathrm{~g} \mathrm{CO} / \mathrm{km}$, the bonus amounts to Euro 1,000; (3) for a car or commercial vehicle emitting $20 \mathrm{~g} \mathrm{CO} 2 / \mathrm{km}$ or less, the bonus amounts to Euro 6,300. EVs are also exempt from the company car tax. Hybrid vehicles emitting less than $110 \mathrm{~g} \mathrm{CO} / \mathrm{km}$ are exempt from the tax during the first two years after registration.

Italy

In many regions, electric vehicles are exempt from the annual circulation tax (ownership tax) for a period of five years from the date of the first registration. After this five-year period, they benefit from a $75 \%$ reduction of the tax rate applied to equivalent gasoline vehicles

Denmark

Electric cars and vans are exempt from registration tax. Hydrogen and fuel cell-powered vehicles are exempt from registration tax until the end of 2018.

\section{United Kingdom}

Electric vehicles (with CO2 emissions below $100 \mathrm{~g} / \mathrm{km}$ ) are exempt from the annual circulation tax, while other alternative fuel cars receive a GBP 10 discount on the paid rates. From 1 April 2010, pure electric cars are exempt from the company car tax, while all cars with $\mathrm{CO} 2$ emissions lower than $50 \mathrm{~g} / \mathrm{km}$ pay $5 \%$ for the tax year 2015/2016.

\section{Spain}

Main city councils (e.g., Madrid, Barcelona, Zaragoza, Valencia, etc.) are reducing the annual circulation tax (ownership tax) for electric and fuel-efficient vehicles by $75 \%$.

China

- Exemption from acquisition and excise tax for electric cars, which range from CNY 35,000 to 60,000 and are based on the engine displacement and price. Under new planned scheme until 2020, owners of "new-energy vehicles," or 4-wheeler EVs, owners will receive subsidies of up to CNY 55,000. Indigenous electric busses are eligible for up to CNY 500,000 in subsidies.

- SGCC, which is the operator and the supplier of EVSEs, has deployed a significant number of charging stations. By mid-2016, China had approximately 81,000 public charging stations. 
Table 3 Power charging standards in key countries

\begin{tabular}{ll}
\hline Country & Power standards \\
\hline Americas & SAE J1772 Level 1 and 2 for Alternate Current (AC) \\
& SAE J1772 Combo Charging System (CCS) Direct \\
& Current (DC) \\
& CHArge-de-MOve (CHAdeMO) (DC) \\
& Tesla Supercharger (DC) \\
& SAE J1772 Level 1 and 2 for Alternate Current (AC) \\
Europe & SAE J1772 CCS DC \\
& CHAdeMO (DC) \\
& IEC 61851 \\
& GuoBiao Recommended (GB/T) (DC) \\
Asia (China) & IEC 61851
\end{tabular}

Table 4 summarizes the key power charging standards along with voltage levels.

To increase BEV adoption, innovative operational and ownership models and electricity rate tariffs are proposed to ensure consumer and grid preparedness. Table 5 summarizes ownership models and installations for charging infrastructure, and electricity rate tariffs, as proposed by the major distribution system utilities in the state of California in the U.S. ${ }^{3}$ The combined budget and total charging stations are USD 227 million, and 12,500 level 1 and level 2, and 100 DCFCs, respectively.

Studies show VGI opportunities, challenges, and multilevel benefits [20]. VGI is increasingly accepted through pilot projects and has shown positive grid impacts. ${ }^{4}$ The BEV battery is used for voltage and frequency regulation to balance supply and demand. With the increase in penetration of wind and solar energy into the Indian grid, voltage and frequency stability will soon be a major concern. During unpredictable peak demands, VGI can be a resource, similar to the TPDDL DR project for commercial and industrial customers (described earlier). EV batteries can also provide emergency backup services during power outages and become a resource for electricity reliability. Consolidated Edison's project in the U.S. opts for demand-side resources-batteries and thermostats-to defer USD 1 billion substation and infrastructure upgrades in congested urban centers at $50 \%$ lower cost [21].

\footnotetext{
${ }^{3}$ California investor-owned utilities' plan for BEV infrastructure rollout to meet the 1 Million EV target by 2020 .

${ }^{4}$ UCLA SMERC is looking at the possibility of $\mathrm{V} 2 \mathrm{G}$ power flow from popular EVs. Exploring how to achieve the maximum V2G power flow from each vehicle, while addressing challenges including response time and power sharing control. The SMERC research in V2G is also focused on facilitating a variety of applications, such as reactive power compensation, voltage regulation and distributed storage, to strengthen the power grid and lead EV usage to an entirely new, smarter era.
}

Table 4 Power charging standards and voltage level

\begin{tabular}{lll}
\hline Charger type & Grid voltage/current & Power to battery \\
\hline CHADeMO & $500 \mathrm{~V} / 125 \mathrm{~A}$ & $62.5 \mathrm{~kW}$ \\
$\mathrm{CCS}$ & $600 \mathrm{~V} / 200 \mathrm{~A}$ & $120 \mathrm{~kW}$ \\
GB/T & $750 \mathrm{~V} / 250 \mathrm{~A}$ & $187.5 \mathrm{~kW}$ \\
AC Level 1 & $108-120 \mathrm{~V} / 15-20 \mathrm{~A}$ & $1.4 \mathrm{~kW}$ \\
AC Level 2 & $208-240 \mathrm{~V} / \geq 30 \mathrm{~A}$ & $7.2-19 \mathrm{~kW}$ \\
\hline
\end{tabular}

Contextual lessons from global experiences can be applied in India and targeted urban centers to develop policies to foster new technologies, programs, and alleviate the grid impacts to accelerate large-scale adoption of BEVs.

\section{Electric Vehicle Adopton in India: Distribution System Impacts in Delhi}

India represents one of the fast growing automobile market in world with vehicle sales increase from 18.5 million per year in 2013-14 to 20.5 million per year in 2015-16. Though EVs are not new in India, the country, however, continues to struggle with the consumer acceptance primarily driven by cost consciousness, lack of charging infrastructure, and EV availability, as key factors. The size of the domestic market for electric vehicles, primarily twowheelers, has seen a drop of $79 \%$ over the past two years. ${ }^{5}$ With recent advancements in electric mobility technologies, lower costs through advanced manufacturing (e.g., leveraging the FAME scheme) and batteries, and ambitious GOI policies and incentives, the consumers and automobile industries seem to be ready to embrace electric mobility. In support the push from the GOI, various private players, nonprofits, and state governments have launched pilot projects around the country in previously unexplored areas such as, grid impacts, systems interoperability, and electrification of public transportation.

To assess the distribution system grid impacts, the study conducted a preliminary case study for the state of Delhi; mainly stemming from the access to data, national capital territory (NCT) of Delhi tax incentive offerings, and the Delhi Pollution Control Committee's "air ambience fund," which is a special tax, collected from sale of diesel fuel [22]. The proceeds of this fund are used for cash subsidies to encourage the adoption of hybrid and EVs. Moreover, the value-added tax on EVs in Delhi is 5\%, which is lower than those for the ICE vehicles (12.5\%) [23]. ${ }^{6}$ The GOI

\footnotetext{
${ }^{5}$ Electric two-wheeler sales dropped from 100,000 units in 2011-12 to 42,000 in 2012-13 and 21,000 in 2013-14

${ }^{6}$ Four Indian states-Chandigarh, Chhattisgarh, Rajasthan, and Uttarakhand -have lower tax for EVs [30-33].
} 
Table 5 BEV charging infrastructure and ownership models in the United States (California)

\begin{tabular}{|c|c|c|c|}
\hline $\begin{array}{l}\text { Ownership } \\
\text { models }\end{array}$ & Description & Installations & $\begin{array}{l}\text { Electricity } \\
\text { rate tariffs }\end{array}$ \\
\hline Customer & $\begin{array}{l}\text { Most widely used } \\
\text { business model for } \\
\text { level } 1 \text { with any } \\
\text { available 108-120 V } \\
\text { outlets and, partially, } \\
\text { for level } 2 \text { charging. }\end{array}$ & $\begin{array}{l}\text { Residential, } \\
\text { building, } \\
\text { and campus } \\
\text { owners }\end{array}$ & $\begin{array}{l}\text { Comprises of } \\
\text { three types: } \\
\text { 1. Dynamic } \\
\text { day-ahead } \\
\text { VGI rate to } \\
\text { driver or host }\end{array}$ \\
\hline Third-party & $\begin{array}{l}\text { Increasingly popular } \\
\text { business model for } \\
\text { level } 2 \text { and DCFCs, } \\
\text { where a charging } \\
\text { station OEM, or a } \\
\text { city/county deploys } \\
\text { charging } \\
\text { infrastructure. }\end{array}$ & $\begin{array}{l}\text { Public } \\
\text { spaces, } \\
\text { highway } \\
\text { corridors }\end{array}$ & $\begin{array}{l}\text { 2. TOU rates } \\
\text { to driver or } \\
\text { host. }\end{array}$ \\
\hline $\begin{array}{c}\text { Electric } \\
\text { utility }\end{array}$ & $\begin{array}{l}\text { Evolving business } \\
\text { model to deploy level } \\
2 \text { and DCFCs in to } \\
\text { support aggressive } \\
\text { national- and state- } \\
\text { level BEV adoption } \\
\text { and zero-emission } \\
\text { vehicle mandates. }\end{array}$ & $\begin{array}{l}\text { Public spaces, } \\
\text { highway } \\
\text { corridors, and } \\
\text { disadvantaged } \\
\text { communities }\end{array}$ & $\begin{array}{l}\text { 3. TOU rates } \\
\text { to host. }\end{array}$ \\
\hline
\end{tabular}

levies an excise duty of up to $30 \%$ on conventional car technologies, while hybrid and electric vehicles are subjected to flat duties of $12.5 \%$ and $6 \%$, respectively [24]. For electric grid management, as stated earlier, the Delhi's distribution utilities have already demonstrated commercial and industrial building AutoDR programs. The study leverages the state of Delhi's actions to understand BEV impacts on the distribution system.

\section{Electric Vehicle Impacts on the Distribution System}

Although India's EV adoption policies look promising, understanding of the impact of BEVs on the distribution grid is under-represented. Though BEVs may have a manageable impact on the power grid as a whole, which has a total generation capacity of $300 \mathrm{GW}$ [25], the local impacts can be significant. At the distribution system level, simultaneous charging of many BEVs under a distribution transformer (DT) circuit can overload if the DT does not have the capacity for aggregated charging. The high-density energy storage charging of BEVs require low- to high-level of electricity, which can impact the DT and the subsequent distribution system that DT is connected to. Fleet of BEVs across DTs
Table 6 Distribution transformer and charging load

\begin{tabular}{llll}
\hline $\begin{array}{l}\text { Transformer } \\
\text { (kVA class) }\end{array}$ & $\begin{array}{l}3.3 \mathrm{~kW} \\
(\text { AC level 2) }\end{array}$ & $\begin{array}{l}6.6 \mathrm{~kW} \\
(\text { AC level 2) }\end{array}$ & $\begin{array}{l}19.2 \mathrm{~kW} \\
(\text { AC level 2) }\end{array}$ \\
\hline 50 & 3 & 1 & 0 \\
75 & 4 & 2 & 0 \\
100 & 6 & 2 & 1 \\
350 & 21 & 10 & 3 \\
630 & 38 & 19 & 6 \\
1250 & 75 & 37 & 12 \\
\hline
\end{tabular}

when charged simultaneously, can demand significant proportion of the daily load from the distribution grid. Some of the challenges the grid can be subjected to are:

1. Excess Distribution System Demand: Fleets of BEV charging during peak hours in a targeted area may cause overloading and failures within the distribution system equipment or lead to excessive power demand, and require expensive upgrades. These factors can cause grid failure, transformer overloading, and even power outages.

2. Increase in Number System Peaks: Simultaneous BEV charging leads to system load peaks (demand) causing supply challenges and power outages, while worsening the conditions for existing system peaks. A stable load curve is one that can match the electricity supply and demand and considers distribution system capacity and the infrastructure.

3. Demand Forecasting Errors from Unmanaged Charging: The randomness of a BEV charging load profile creates daily load forecasting problems. Accurate forecasts lead to substantial savings in grid operating and maintenance costs, increased reliability of power supply and delivery system, and support correct decisions for upgrades. Since, BEVs are a mobile load within the electric grid system, it is difficult to forecast when (temporal) and where (spatial) the demand is required.

The DT capacity is a major barrier for EV charging at the distribution system domain, which struts at the last mile connectivity to the consumers. Considering a typical loading capacity at $80 \%$ of the peak load, Table 6 estimates the number of level $2 \mathrm{EV}$ chargers that can be connected to a DT. ${ }^{7}$ The more pervasive the overloading of DTs, the more will be the system-wide impacts and the need for expensive upgrades to the distribution system.

Studies show that BEV owners charge their vehicles upon reaching home at the end of a working day or, in countries

\footnotetext{
${ }^{7}$ The loading capacity was estimated done under the guidance of a large Indian utility, TATA Power, Mumbai.
} 
Table 7 Vehicle growth estimates (2022): Delhi

\begin{tabular}{lccccc}
\hline & $\begin{array}{l}\text { Total } \\
\text { vehicles } \\
(2014)\end{array}$ & $\begin{array}{l}\text { Estimated } \\
\text { vehicles } \\
\text { in 2022 }\end{array}$ & $\begin{array}{l}\text { Estimate } \\
\text { of EV } \% \\
\text { in 2022 }\end{array}$ & $\begin{array}{l}\text { Estimate } \\
\text { of EVs } \\
\text { in 2022 }\end{array}$ & $\begin{array}{l}\text { Estimate } \\
\text { of EVs } \\
\text { in 2022 }\end{array}$ \\
\hline Private 4-W & 4899733 & 2022186 & $1 \%$ & 20222 & 240033 \\
Taxis & 236307 & 159567 & $10 \%$ & 15957 & \\
Busses & 32048 & 11124 & $10 \%$ & 1112 & \\
Other public & 50327 & 26896 & $50 \%$ & 20226 & \\
transport & & & & 21440 & \\
Freight vehicles & 246157 & 85761 & $25 \%$ & 155793 & \\
2-W & 8845660 & 3115868 & $5 \%$ & 5283 & \\
3-W & 90938 & 10565 & $50 \%$ & & \\
\hline
\end{tabular}

such, as the U.S., at workplaces for daytime charging within the building or campus network [17]. The study also estimates that in the U.S., VGI services save USD 4,000 over an 8-year ownership life of an EV or USD 500/year from market payments and lower electricity bills. Unmanaged $\mathrm{BEV}$ charging can coincide with both afternoon and evening peak time demand to aggravate the peak demand problem. Distribution utilities are subjected to the challenges of multiple customers charging on the same transformer with limited capacity. To further understand the distribution system impact, sensitivity analysis was conducted for the state of Delhi.

\section{Charging Initiatives by the Distribution Utilities}

Some distribution utilities have initiated early-stage EV charging networks, which were triggered by the early years of MNREs subsidy to utilities to promote EVs through corporate and social responsibility programs. The state of Delhi has six distribution unities-BSES Rajdhani Power Limited, BSES Yamuna Power Limited, Delhi Transco Limited, Indraprastha Power Generation Company Limited, Delhi
Power Company Limited, and TPDDL. The following are the charging station ownership and operation practices by TPDDL and BSES-Delhi.

TPDDL has installed "EV Charging Centers" at five locations across its territory for Mahindra Reva BEV owners where an aggregated 200 cars are charged [26]. These charging centers are located in areas with enough power capacity and within the $66 \mathrm{kV}$ and $33 \mathrm{kV}$ high- and medium-voltage network, respectively. TPDDL has also installed free public charging stations for 2-wheelers for the first time in Delhi with anticipated support to 10,000 vehicles [27]. Two BSES Delhi affiliates-BSES Rajdhani Power Limited (BRPL) and BSES Yamuna Power Limited (BYPL) — have installed charging infrastructure to encourage the use of BEVs. While BRPL has installed two BEV charging stations at BRPL's office in RK Puram and Lodhi Colony residential neighborhood, BYPL has a network of $50 \mathrm{EV}$ charging station ports within the $66 \mathrm{kV}, 33 \mathrm{kV}$, and $11 \mathrm{kV}$, high-, medium-, and low-voltage network, respectively [28, 29].

While both TPDDL and BSES initiatives are welcome, the large-scale growth in EVs necessitates charging infrastructure and in the low-voltage network-between $100 \mathrm{~V}$
Fig. 1 Estimated Delhi's summer demand load curves for 2022

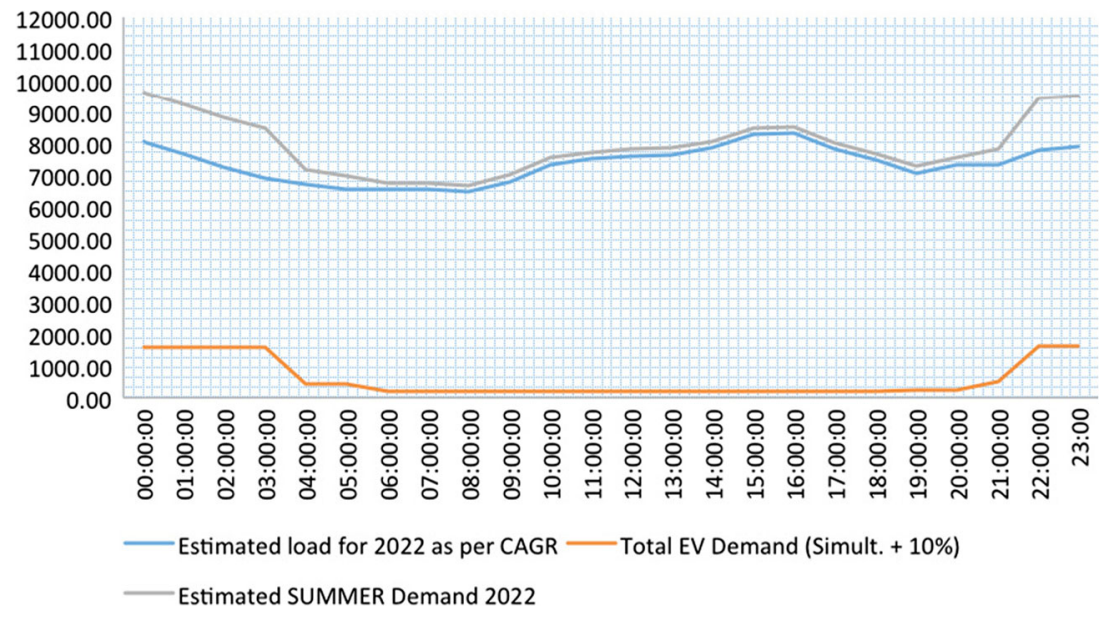


Fig. 2 Estimated Delhi's winter demand load curves for 2022

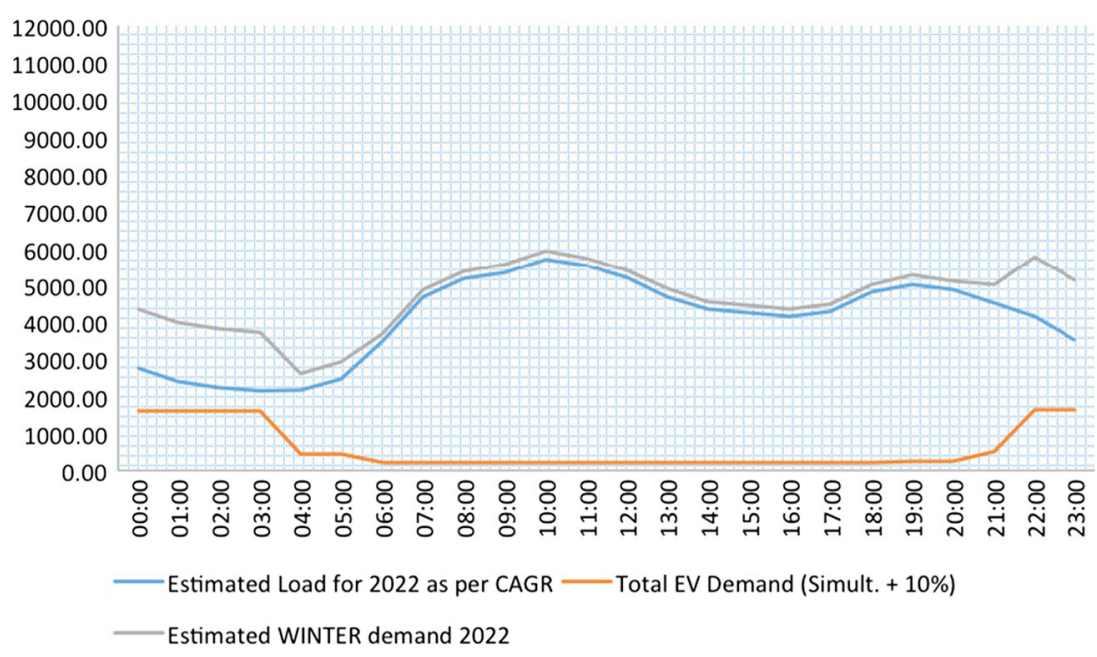

to $1000 \mathrm{~V}$-and regions closer to customers (e.g., traffic corridors, public spaces, petrol pumps, neighborhoods, workplaces, residences).

\section{Peak Electric Demand Estimation: City of Delhi}

The 18th electrical power survey conducted in 2013 by India's Central Electricity Authority was used, as an estimate of Delhi's peak power demand by 2021-22. This data was used to estimate hourly load curves. The following methodology was used to estimate hourly load. These estimates assume that the characteristics of distribution system, system capacities, and demand from year 2014 will scale linearly to the year 2021-22.

In July 2014,

- Delhi system peak demand in 2014: 5,925 MW

- Delhi power demand at 3 AM in 2014: 4,513 MW

- Nighttime peak load factor $=76 \%$

Thus, estimates for July 2022,

- Delhi system peak demand in 2022: 9,024 MW

- 2014 baseline peak load factor at 3 AM: $76 \%$

- Delhi power demand at $3 \mathrm{AM}$ in $2022=6,874 \mathrm{MW}$

\section{Estimation for Number of Vehicles}

The number of vehicles in Delhi in 2014, which was obtained from the transportation department, was used to estimate the total number of vehicles in 2022. Using the previous vehicular adoption data, the number of vehicles in 2022 was estimated by Compounded Annual Growth Rate (CAGR). The assumed adoption for each vehicle class is applied for new registrations after 2014, as Delhi has no significant adoption of BEVs and noticeable grid impacts. Table 7 summarizes the results.

\footnotetext{
${ }^{8}$ As per 18th Electrical Power Survey conducted in 2013
}

\section{Electric Load from Battery Electric Vehicles}

For the analysis of resulting electric demand growth, we assume that BEVs would not be charged simultaneously and $10 \%$ of BEVs, which will always be connected to the distribution grid and charging. Additionally, different categories of vehicles like 3-wheelers, private 4-wheelers; taxis; busses and business goods carriers are considered and their required charging level are assumed. Thus, the hourly load profile according to different charging profiles and BEV types (commercial or private) are stated. Additional key assumptions are:

- While calculating the load of BEV on grid, only a certain percentage of vehicles and types are connected to the grid simultaneously.

- It is also assumed that in 2022 , hourly load data will be proportionally scaled from 2014.

- We assume that out of $40 \%$ simultaneous charging for 2- and 4-wheelers, $10 \%$ of the 2- and 4-wheelers will be charged outside the residential network.

- To the total number of 3W estimated by the India Smart Grid Forum (ISGF) based on CAGR in 2022, we have additionally added 5Lakh electric rickshaw as per our previous estimations.

- Each BEV category uses different charging levels:

$$
\begin{aligned}
& \text { - Cars: } 6.6 \mathrm{~kW} \text { charger } \\
& \text { - } \\
& \text { - } \\
& \text { - 3us: } 60 \mathrm{~kW} \text { charger } \\
& \text { - } \\
& \text { - 2-wheeler: } 480 \mathrm{~W} \text { charger }^{11} \\
&
\end{aligned}
$$

\footnotetext{
${ }^{9}$ Based on Level 2 workplace charging and select residential charging in the U.S. and European countries.

${ }^{10} \mathrm{Based}$ on charger levels introduced by BYD busses in Bangalore

${ }^{11}$ Based on the ISGF study.

${ }^{12}$ The charger level for 2 -wheelers is assumed to support equivalent ICE vehicle versions. It is possible that the future scenarios may standardize charging power levels across different BEV categories.
} 
Figures 1 and 2 summarize the estimated electricity load profile in 2022, as per CAGR, and estimated demand from BEVs at $10 \%$ simultaneous charging, and peak summer demand for Delhi.

The summer and winter load analysis results show that while afternoon peak marginally increases, the system-wide peak impacts during the evening and night are more pronounced. This is primarily due to assumptions that majority of the BEV consumers will charge during non-working hours. Obviously, these estimates need to be assessed based on India's plans to support aggressive workplace charging.

\section{Conclusions and Recommended Next Steps}

The study reviewed macro- and micro-level initiatives in India to scale and accelerate $\mathrm{EV}$ adoption to meet the NEMM 2020 and FAME goals. A review of global practices for EV adoption was conducted for BEVs. The study performed a limited and preliminary review of the BEVs' impact on Delhi's distribution system by analyzing load profiles and estimating the growth. To accelerate BEV adoption, consumer engagement, and integrated grid, the following are key conclusions. Accordingly, the recommendations are listed under adoption practices, consumer incentives, and power systems planning.

- To accelerate BEV adoption, Indian policy makers and regulations must consider global practices, while considering local requirements such as cost, electricity network, and consumer charging behavior. India must develop specific EV needs for the Indian conditions and work with global and local original equipment manufacturers (OEM) and experts to meet the NEMM 2020 plan and FAME goals. For example, the lion share for FAME scheme's demand incentive component lacks adequate focus on charging infrastructure and research needs to understand and future-proof unique vehicle and electricity distribution needs in India-all relative to global practices.

- To engage cost-sensitive consumers, Indian nationaland state-level regulations must consider total cost of ownership-based incentives to lower BEV and EVSE ownership costs through mechanisms such as tax credits, lower production costs for OEMs, reduced sales taxes, etc., which can be funded from oil subsidy and import savings, $\mathrm{CO} 2$ reduction, and innovative financing mechanisms. BEVs also provide other non-tangible societal benefits such, as urban air-quality improvements and better quality of health.

- Regulators, system operators, and utilities must consider localized and integrated power system impacts of BEVs. The VGI has the potential to mitigate or defer system upgrade costs, which can also support higher penetration of renewables. With managed charging technologies, BEVs can be charged without any restrictions and electricity rate tariffs can be designed to offer incentives to modulate consumer-charging behavior, and building codes that mandate residential and workplace charging infrastructure.

\section{References}

1. Bloomberg New Energy Finance, New Energy Outlook (2016) Long-term projects of the global energy sector

2. All India study report to petroleum planning and analysis cell on sale of diesel and petrol. Press Information Bureau, Government of India, 2014. Accessible at http://pib.nic.in/newsite/PrintRelease. aspx? relid $=102799$

3. Goldman Sachs, India: how much energy? Asia Economics Analyst, Issue No: 14/25 (2014)

4. U.S. Energy Information Administration (EIA), Country Analysis Brief: India (2016)

5. Society of Indian Automobile Manufacturers (SIAM), Accessible at http://www.siamindia.com/statistics.aspx?mpgid=8\& pgidtrail $=14$

6. The Hindu Business Online, Accessible at http://www.thehindubusinessline.com/news/govt-earmarks-rs-1000-cr-to-boost-electricvehicle-sales/article6792232.ece

7. Rokadiya S, Bandivadekar A (2016) Hybrid and electric vehicles in India: current scenario and market incentives. The International Council on Clean Transportation (ICCT)

8. Yin R, Ghatikar G, Deshmukh R, Khan A (2015) Findings from an advanced demand response smart grid project to improve electricity reliability in India. In: Proceedings of the India smart grid week, New-Delhi. LBNL-6982E

9. Ghatikar G, Yin R, Deshmukh R, Das GG (2015) Characterization and effectiveness of technologies for India's electric grid reliability and energy security. In: Proceedings of the India smart grid week, New-Delhi. LBNL-6994E

10. Deshmukh R, Ghatikar G, Yin R, Das G, Saha S (2015) Estimation of potential and value of demand response for industrial and commercial consumers in Delhi. In: Proceedings of the India Smart grid week, New-Delhi. LBNL-6987E

11. CalGreen (2015) Intervening code cycle. Significant changesresidential measures, effective July 1

12. European Automobile Manufacturers Association, Alternate fuel vehicle registration, in press

13. French Building Code, Decree no. 2016-968 of 13 July 2016; http://www.avere-france.org/Uploads/Documents/1468860827ed 6bb57e980cf9e0be18453638a79929-D\%C3\%A9cret\%2013\%20 juillet\%202016.pdf

14. Platform for electric mobility, accelerating electric infrastructure deployment in Europe. Position Paper of the Platform for ElectroMobility, Brussels (2016)

15. EV-Volumes, China Plug-in Sales 2016 Q4 and Full Year, in press

16. EV-Volumes, Global plug-in sales for 2016, in press

17. US Department of Energy (DOE) (2015) Plugged In: how Americans charge their electric vehicles, INL/EXT-15-35584

18. Tesla, Electric vehicle incentives. Accessible at https://www.tesla. com/support/incentives

19. European Automobile Manufacturers Association. Overview of purchase and tax incentives for electric vehicles in the eu in 2016, in press 
20. Ghatikar G Decoding power systems' integration for clean transportation and decarbonized electric grid. In: Proceedings of the ISGW 2016. New Delhi, India. https://doi.org/10.13140/RG.2.1. 3555.4960

21. Greentech Media (2016) Demand-side resources can be cheaper than large infrastructure upgrades. Accessed at https://www.green techmedia.com/articles/read/distributed-resources-gain-traction-toavoid-grid-upgrades

22. Government of NCT of Delhi, Department of Environment. Accessed at http://www.delhi.gov.in/wps/wcm/connect/environment/Environment/Home/Environmental+Issues/Ambient+Air+Quality

23. Budget 2016-17, Government of NCT of Delhi. Accessed at http://delhi.gov.in/wps/wcm/connect/DoIT_Planning/planning/ budget+of+delhi/budget+2016-17

24. Economic Times (in press) Delhi government reduces VAT on hybrid cars

25. Central Electricity Authority (CEA), India; All India Installed Capacity of Power Stations, as of March 31, 2016. Accessed from www.cea.nic.in/reports/monthly/installedcapacity/2016/installed_ capacity-03.pdf

26. Tata Power Delhi Distribution Limited (TPDDL), Press Releases. http://www.ndpl.com/press-release-details.aspx?this=199id=57686 (Accessed January 1, 2017)
27. Tata Power Delhi Distribution Limited (TPDDL), Press Releases. http://www.ndpl.com/press-release-details.aspx?this=199\&id=1089 (Accessed January 1, 2017)

28. BSES Delhi, Initiatives Undertaken, http://www.bsesdelhi.com/ HTML/wb_in_undertaken.html (Accessed January 1, 2017)

29. BSES Delhi, EV Charging Promotion Material, http://www. bsesdelhi.com/docs/pdf/Chargeports_Leaflet.pdf

30. VAT Schedules, Excise and Taxation Department, Chandigarh Administration. Accessed at http://etdut.gov.in/ExciseOnline/ download.html

31. VAT Rate, Commercial Tax Department, Government of Chhattisgarh. Accessed at http://comtax.cg.nic.in/pages/tax_rates.htm

32. VAT Schedules, Commercial Taxes Department, Government of Rajasthan. Accessed at http://rajtax.gov.in/vatweb/download/ Help/VAT.pdf

33. Tax Rates. Commercial Tax Department, Government of Uttarakhand, Accessed at http://comtax.uk.gov.in/pages/show/1674tax-rates

34. Organization for Economic Cooperation and Development (OECD) and International Energy Agency (IEA), Global EV Outlook 2016: Beyond 1 millon electric cars (2016) 